\title{
Antecedents of Work-Family Conflict: Review and Prospect
}

\author{
Jianwei Zhang \\ School of Management and Economics, Beijing Institute of Technology \\ 5 South Zhongguancun Street, Haidian District, Beijing100081, China \\ Tel: 86-10-6891-8455Ｅ-mail: jianweizhang@263.net \\ Yuxin Liu \\ Business School, University of International Business and Economics \\ No.10 Huixin Dongjie, Chaoyang District, Beijing 100029, China \\ Tel: 86-10-6449-4298Ｅ-mail: Liuyx21@263.net
}

\begin{abstract}
With the increase in the proportion of dual-earner families and work stress, there are increasing emphases placed on the study of work-family conflict (WFC). The paper reviews that antecedents of WFC from aspects of individual, work and family. Findings and implications include the effects of individual factors like demographic and personality variables, the influences of work variables like work stress, family friendly programs and impacts of family variables like family demands and spousal interactions. In addition, we propose that more efforts should be put into theoretical development, integrative studies, individual and family variables in the future.
\end{abstract}

Keywords: Work-family conflict, Antecedents, Workaholism, Personality, Family friendly programs

Work and family are defined as two main fields in which modern people live. They satisfy human's various demands and also the sources of people's happiness simultaneously. In recent decades, owing to rising proportion of dual-earner families, increasing work stress and growing emphasis on quality of life, much more attentions have been paid to work-family conflict (WFC). Work-family conflict (WFC) referring to the roles conflict is generated when the stress from work and family can't be coordinated in some aspects (Greenhaus, J. H. \& Beutell, N.J, 1985). Greenhaus and Beutell (1985) classified WFC into three types, i.e. conflict based on time, conflict based on stress and conflict based on behavior. Gutek et al has found out that all types of WFC are bidirectional, including work-to-family conflict, work interference with family (WIF) and family-to-work conflict, and family interference with work (FIW). So, six dimensions are formed correspondingly (Gutek, B. A. et al, 1991). According to the researches, WFC widely influences health (bibulosity, depression), work (work satisfaction, vocation ambition) and family (family happiness) (Eby, L. T. et al, 2005). Thus, scholars all along have made efforts to seek all various influential factors on WFC, and have achieved some research findings. Reviewing and summarizing the achieved literatures can not only help us to make the future research direction in the field definitely, but also establish basis for organizations and individuals to cope with WFC effectively and to balance work and family practically.

The main purpose of the current study is to elaborate the influential factors of WFC from three levels, i.e. individual, work and family. Furthermore, future research direction also proposed through analyzing the shortage of existing researches.

\section{The influence of variables in individual field}

The individual variables that influence WFC mainly belong to demographic variables and personality traits on existing research.

\subsection{Demographic variables}

The demographic variables influential to WFC consist of gender, income, lifetime employment status, level of education, marital status, child status, and so on. The last two will be introduced in the section of family variables.

\subsubsection{Gender}

Almost all the researches on WFC have come down to gender differences. These studies not only are limited 
within the horizontal differences on a variety of WFC between two genders (Behson, S. J., 2002), but also find out the gender differences of WFC on prediction sources of work and family (Wallace, J. E., 1999). Additionally, it has been proved that the relationship between WFC and result variable is different between genders (Duxbury, L. E., \& Higgins, C. A., 1991).

Most of the studies have demonstrated the above gender differences in each field of WFC, but definite results are not all the same. Luo Yaoping (2007) classified the results of horizontal gender differences of WFC into three categories: (1) females experience more WIF and FIW than males; (2) males experience more WIF than females; (3) females experience more WIF than males (Perkins, H. Wesley, and DeMeis, Debra K., 1996), but there is no gender difference on FIW. A plenty of studies indicated that females may take on much more family responsibility than males, so females are easily fettered by family, which results in FIW. Other researches also demonstrated that females are more likely to experience FIW than males (Carnicer, M.P.D., 2004). Milkie (1999) pointed out that family duty hampers females participating work more, and that females are easier to get work stress and family stress and more difficult to balance work and family as well, and therefore, more likely to experience FIW.

However, some scholars inclined to the opposite point. They think that males will inevitably take more family responsibility as more and more females get jobs. From a certain perspective, males are experiencing the same FIW as females psychologically (Frone, M. R. et al, 1997). Furthermore, influenced by traditional ideas, society won't reduce any expectation on males' work commitment even if they contribute much more to housework. Therefore, it is easier for males to feel the dual stress from both family and work, which results in higher level of FIW (Northcraft, G. B. et al, 1988).

The researches not only found out the gender's differences of FIW, but also observed WIF from gender's perspective. Gutek discovered that the WIF phenomenon brought by time conflict is quite common. Although males and females spend the same time on their work, females WIF is more obvious than males', probably because females focus more on family. Meanwhile, as females spend more time on housework, work might more disturb family: they probably experience more WIF than males. Longtime work and fulfilling family duty enable females feel stronger WIF (Simon, R. W., 1995).

Although there are many debates, one point of these views is widely accepted that is not gender per se, but the gender role that people hold is working. The effects of gender role, including gender identification and gender role attitude, are significantly embodied on the faith of work and family (Matsui, T. et al, 1999), work after birth of baby, and so on. The research also found out that females are always the main undertakers of childcare and housework no matter they work or not (Lundberg, U., \& Frankenhaeuser, M., 1999). Moreover, females are more likely to encounter interruptive career than males (Kirchmeyer, C., 1998). All these points represent the influences of consciousness of gender role.

\subsubsection{Income}

The research on the relationship between income and WFC can't come to an agreement. Some researchers have not found any significant correlation (Frone, M. R. et al, 1997), while others have discovered positive correlation between income and WIF, but that of FIW is not apparent (Frone,M.R., 2000). The reason might be that along with increasing income, work function and task increasing as well. In addition, some researchers showed opposite points to this. The study of Voydanoff and Kelly (1984) indicated that high-income people feel less shortage of time compared to low-income ones. Their presuming economic strength probably helps to satisfy them on time demand.

\subsubsection{Lifelong employment status}

In WFC field, the research on lifelong employment status is comparatively rare. Generally speaking, along with increasing experience in organizations, the possibility that staff feel conflict will decrease. Employees who feel high conflict may choose to leave (Netemeyer, R.G. et al, 1996), or gradually learning to confront conflict. Therefore, the researchers infer that the staff with lifelong employment status experience less role conflict. However, the revealed correlation between it and WIF has not been confirmed (Beutell, N., \& Wittig-Berman, U., 1999). But since new staff has not established countermeasure system to work stress, they are more sensitive to it and apperceive higher work requirement. Lifelong employment status might be an important work variable of influencing the work requirement that individual apperceives. It maybe directly influences WFC. The relationship between these two factors needs to be further investigated.

\subsubsection{Level of education}

Sanik (1993) found out that level of education influences WFC. Maybe since that level of education can intensify 
the behavior of estranging family and joining organizations. Higher educated persons would obtain more opportunities of promotion or out-of-town work, which increases the possibility of WIF (Adams, G. A. et al, 1996). Level of education is also interactive with gender. Carnicer (2004) discovered that higher educated males experience higher FIW, while lower educated females feel lower. On the contrary, level of education has no apparent influence on WIF. This discovery also showed that for higher educated males (usually on high post), family responsibility makes them feel difficult to concentrate on work; and for lower educated females FIW is lower probably because they are usually engaged in part-time jobs and it is easier for them to pay attention to housework.

\subsection{Personality}

Among the antecedents of WFC, personality gets more attentions, mainly including self-efficacy, "big-five" personality and workaholism.

\subsubsection{On the relationship between self-efficacy and WFC}

"Self-efficacy" was firstly raised by Bandura (1977), a famous American psychologist. Bandura thinks that self-efficacy refers to "the self-confidence whether people can make use of held skill to fulfill one certain job". Self-efficacy is the prospect whether behavioral subject is able to operate certain types of behavior in particular condition or not. It could be regarded as a kind of state and trait as well. In other words, there exists a sort of summarized self-efficacy, also called General Self-efficacy, i.e. GSE. GSE directly influences individual functional effect of psychological process as taking action. It plays a very important role in self-regulating system.

Research showed that self-efficacy is significantly correlative with WFC (Bernas, K. H., \& Major, A. D., 2000). Hennessy's research (2007) not only supported this result, but also found the regulating effect of self-efficacy between WFC and family satisfaction.

Rachel studied the self-efficacy of two genders as parents (Cinamon, G.R. et al, 2007). They found out that males perceive higher self-efficacy as parents than females. For females, they also claimed that, self-efficacy as parents is significantly negatively correlative with WIF and FIW, while it is only significantly negatively correlative with WIF for males. Chen Hua and Tan Kaiyi et al (2007) proposed that all factors of self-efficacy are significantly negatively correlated with WIF and FIW.

Erdwins et al (2001) investigated the relationship of WFC and role overload to social support, role satisfaction, and self-efficacy. Their research showed that work-family self-efficacy is an important antecedent variable of female's WFC. Self-efficacy and WFC are negatively correlative. As female's work family role of self-efficacy increases, their WFC goes down. Cinamon (2006) studied the relationship among WFC, self-efficacy, gender and family background, and found that self-efficacy is negatively correlative with WIF and FIW.

Yu Shuguang (2008) made elaborate classification of WFC. He found out that general self-efficacy is negatively correlative with stress-based WIF, behavior-based WIF, time-based FIW, stress-based FIW and behavior-based FIW, but positively correlative with time-based WIF. In addition, he also detected that general self-efficacy (GSE) can adjust the effects of WIF and FIW to work satisfaction, family satisfaction and subject well-being. The negative effects of WIF and FIW to the above variables will be weakened while the GSE is increasing.

Why does GSE influence WFC? We think that the description of self-efficacy by Wood and Bandura may elaborate the inherent effect system of the influence. They proposed (Wood, R. \& Bandura, A., 1989) self-efficacy work by influencing people's choice of behavior, target making, level of effort to behavior, and perseverance. According to this inference the individuals with high self-efficacy usually have strong initiative whenever they choose to work or organize family. And this strong initiative may help them avoid some WFC. Moreover, high-self-efficacy people always think they can control WFC, so they will make more efforts to avoid or reduce WFC. Additionally, self-efficacy can indirectly influence WFC through acting on individual perception and emotion.

\subsubsection{On the relationship between "Big Five Personality" and WFC}

"Big five" personality theory begins to attract attentions in recent years, but the research on the relationship between it and WFC is quite few. Bruck and Allen made a systematical study on that. They declared (Bruck, C.S. $\&$ Allen, T.D., 2003) that conscientiousness is not significantly correlative with the three types of WFC. And the same time, they also found that conscientious people experience less FIW. Probably conscientiousness-related plan and organization skill could help them to avoid FIW. Bruck and Allen also discovered that after controlling the effect of negative affectivity and Type A personality, conscientiousness still has significant and negative prediction effect on FIW. Shafiro's (2004) research showed that conscientiousness is correlated with the 
following four types of conflict: time-based FIW, stress-based FIW, behavior-based WIF and FIW. High conscientious people experience less the above conflicts than low conscientious ones. Wayne (2004) claimed that high conscientious people experience comparatively low WIF and FIW.

A research finding also showed (Bruck, C.S. \& Allen , T.D., 2003), as far as the relationship of the two variables, neuroticism is significantly positively correlative with WFC whole, WIF, FIW, time-based WFC and stress-based WFC. However, after controlling type A personality, negative affectivity and other personality variables of "big five", neuroticism has no significantly regressive coefficient to WFC whole, WIF and FIW. The above studies by Wayne et al also indicated that neuroticism is significantly positively correlative with WIF and FIW. Andreassi (2006) found out that the relation of neuroticism and WIF is higher than that of neuroticism and FIW.

Bruck et al noticed that as for the relationship between two variables, agreeableness has significantly negative correlation with WFC whole, WIF, FIW, time-based WFC and stress-based WFC. However, after controlling type A personality, negative affectivity and other personality variables of "big five", agreeableness is still the significantly negative predictor of time-based WFC, but has no significant influence on other types of conflict, WIF and FIW. The above studies by Wayne et al showed that agreeableness has significantly negative correlation with WIF, but not significant with FIW. As for extraversion and openness, Bruck et al neither found any significant correlation of them and various or all types of WFC, nor significant prediction effect in the regressive analysis in which they are as independent variables together with other personality variables.

\subsubsection{On the relationship between workaholism and WFC}

Workaholism first attracted attention of mass media. Academe has started real empirical research since $21^{\text {st }}$ Century. Researchers defined workaholism mainly from the dimensions of work-involved, work drive, work interest, and classified them into blue workaholic and enthusiastic workaholic (McMillan, L.H.W., 2002). The two types of workaholic both have high "work battery", but "blue workaholic" has less work pleasure, while "enthusiastic workaholic" gets more fun of work.

What are the advantages and disadvantages of workaholism? Should we promote or oppose it? Due to lack of common-approved operative definition and measurement tools, relevant empirical research is hampered. Burke noticed (1999) workaholism is negatively correlative with satisfaction on amateur life. Russo et al investigated the relationship between workaholism and WFC directly (Russo, J.A., \& Waters, L.E., 2006). And they have found out that the staff type is significantly correlative with WFC. Compared with relaxed and uninvolved staff, the above two types of workaholic have higher WFC. Furthermore, staff type has regulative effect between flexible working hour and WFC. Definitely speaking, flexible working hour can reduce the WFC of "enthusiastic workaholic", but can't relieve that of "blue workaholic".

According to the above literature, workaholism probably influences WFC through two approaches. Firstly, workaholism gets relation with WFC by a middle variable, such as working hour. Some researchers have demonstrated that working hour and WFC have two-way connection (Fu, C.K. \& Shaffer, M.A., 2001). The study on workaholism showed, compared with relaxed and uninvolved staff, blue workaholic and enthusiastic workaholic spend much more time on work (Spence, T.J. \& Robbins, A.S., 1992). Therefore, systematically analyzed, working hour might be one reason of the correlation between workaholism and WFC. And this correlation is achieved as workaholic encourages staff to spend much more time on work. Secondly, workaholism and WFC get correlative through sharing a certain characteristic antecedent variable. One research showed (Bruck, C.S. \& Allen, T.D., 2003) type A personality is correlated with both workaholism and WFC. Definitely speaking, among type A personalities, "impatience-irritability" dimension has moderated correlation with both intrinsic force in workaholism scale and WFC.

\section{The influence of work variables}

The research on the variables within work field which influences WFC mainly represents in four aspects: work character, work stress, family friendly programs and highly-committed work system.

\subsection{Work character}

Although the research results on this topic are rather different, it is generally believed that work character has direct influence on WIF. The variables involved in work character are quite scattered, mostly including working hours, working initiative, profession character, etc.

Some existing researches have touched upon the effects of working hours on WIF, FIW and integrated WFC. By investigating over 8000 staffs (Frone, M.R., 2000), Frone (1997) discovered that the correlation coefficient of working hour and WIF is 0.20 . A lot of research shows, with the increasing in working hours, employees experience higher work demands. So working hour is positively correlative with WIF. Some other researchers 
pointed out that working hour has positive correlation with whole WFC (Stoner, C.R. et al, 1991), but did not find any significant relations with FIW. In addition, the employees with longer working hours per day or in total working days have significantly higher WIF than others (Nielson, T. R.et al, 2001). In short, present research evidence shows that working hours have significant influence on WIF, but not FIW.

Working initiative or controllability would influence WFC as well. Thomas et al (1995) pointed out that initiative of planning working hour and WFC are negatively correlative. Additionally, different from most researches, Adams and Jex (1999) found out that controllability of working hour can predict FIW. This discovery indicated the initiative of working hour may enable individuals to consider family demand when they plan working hour, so as to avoid the rebound of family demand and FIW.

The influences of work character on WFC also can obtain support from the role theory which is an important theoretical base of WFC research. According to it, a particular working role involves a series of expectations, demands, and interpersonal interactions related to this social position. The particular behavioral mode of a particular role might be uncoordinated with the behavioral expectation of another role, which results in behavior-based WFC. The physical and social environment of individual work can be inferred by profession, and then their behaviors and attitudes will be predicted subsequently. Moreover, profession partially influences individual management mode on boundary of work and family (Olson-Buchanan, J., \& Boswell, W., 2006). Dierdorff et al (2008) made an empirical test in 2008 showing that profession significantly influence WFC. The "interdependence" and "responsibility" of profession can predict its WFC.

\subsection{Work stress}

Work stress is closely relative to WFC. Work stress is composed of role conflict, role vagueness, role strain, and other dimensions. Most of WFC research models regard role conflict, role vagueness, and role strain as important influential variables. Each of these stress sources may influence WFC. Many researches showed that the conflict, stress and nervousness from work are all correlated to WFC (Grzywacz, J. G., \& Marks, N. F., 2000).

As far as work role conflict is concerned, the more serious models between work roles, the easier these stresses spill over to family role. As early as Greenhaus et al (1987) found out that role conflict is significantly correlated with WIF. Role vagueness refers to individual uncertain status to his or her role expectation. Vague work role is not only positively correlative with WFC, but also significantly with FIW (Carlson, D.S., \& Kacmar, K. M., 2000). Role strain means individual self-perception is in a state of "too much work, too little time" (Caplan, R. D. et al, 1975). Greenhaus and Beutell held (Greenhaus, J. H. \& Beutell, N.J, 1985)that the stress brought by a kind of role (such as "work") may enable a person to dissatisfy the expectation of another kind of role (such as "family"), which is consistent with Hobfoll's theory of resource conservation. According to the theory of resource conservation, time and energy will be exhausted. Once they are used up, other activities, in the same field or different ones, can not use these resources any more. In other words, the high demand and high expectation of one kind of role (such as "work") will limit the resource of another kind of role (such as "family"). The research showed work role strain has significantly positive correlation with WIF and FIW (Aryee, S., Luk, V. et al, 1999).

Additionally, the researchers have also studied the relationship of some work-strain-related factors, such as work demand, work devotion, work-dedicated, and WFC. Through the researches, they have noticed that the following people with higher WFC than others: self-reported high-work-devotion people (Parasurman, S., \& Simmers, C. A., 2001), higher-work-demand people (Yang, N. et al, 2000) (Chinese sample), high-work-dedicated people (Parasurman, S., \& Simmers, C. A., 2001) (especially boss themselves), and strong-internal-motivation and high-organization-loyalty people (Tenbrunsel, A. E. et al, 1995). Hall and Richter (1988) stated that the more an individual devotes into work role, the greater possibility he may bring work problems back home, and the bigger of WFC. In other words, high devotion into work is unavoidable to cause individual sacrifice of family life and to result in WFC.

\subsection{Family friendly programs}

Aiming at WFC issue, more and more organizations starting to launch management measures like "family friendly programs" to confront. Family friendly programs have variety of contents, generally including flexible working system, supporting plan and other measures. Flexible working system is basically classified into working system centering on time flexibility (also called flexible working hour system) and working system centering on place flexibility. Flexible working hour system mainly consists of flextime, compressed workweek, work share, and so on. Working system centering on place flexibility mostly refers to telecommuting. 
Although family friendly programs attract more and more organizations' attentions, the research on testing their effects on relieve of WFC is quite scarcely. Thompson et al realized (Thompson, C.A. et al, 1999) that many family friendly programs (such as flextime, work share, etc) can correspondingly reduce the WFC. Aryee et al (1999) also noticed that control of working hours is significantly correlative with reduction of WFC. Flexible working hour system definitely has positive effect on reducing WFC and improving life quality of staff. Chen Weizheng et al (2007), Chinese scholars, claimed that the implementation of work share can relieve the WFC and promote the work-life balance. However, some researchers are opposite to this. Some research showed (Carnicer, M.P.D., 2004) that working flexibility is positively correlative with males' WFC, but not significant with females'. So, researchers speculated that the reason might be that high working flexibility provides males much more chances to take on family responsibility, which increases the possibility of conflict to traditional role consciousness.

There are some disputes to the influence of telecommuting on WFC. On one hand, telecommuting increases boundary flexibility so as to help employees synchronize work and family demand and reduce WFC. Based on these sorts of flexibility, employees are allowed to arrange optimal working time in order to reduce the family interference as much as possible and also relieve the infiltrative negative influences. Employees can establish independent working space at home to prevent from family members' interference. Although telecommuting staff spend much longer working hours, they save commuting times which could be used for family activities, so that time-based conflict will be reduced. On the other hand, for telecommuting working, as family and work occupy the same place, they may invade each other. So the possibility about that work is infiltrative to life boundary will be increased, which results in WFC potentially. This infiltration still can make a person hard to escape from work and increase the possibility of time-based conflict. Furthermore, telecommuting may encourage employees to continue working after normal working hours. So it is difficult for them to separate family from work (Olson-Buchanan, J., \& Boswell, W., 2006). Meta-analysis showed (Gajendran, R.S., \& Harrison, D.A., 2007) that telecommuting has little effect on WFC, but the effect is positive. Simultaneously, high strength of telecommuting increases good influence on WFC, but it is harmful to the fellow's relationship.

In addition, as important parts of family friendly programs, backup organization culture, managers or supervisors have universal and positive effects on reducing WFC (Clark, S. C., 2002). Paying attention to family demand and implement flexible working in management both will strengthen the sense of community and work control, and thus reduce WFC. However, there is still disagreement. For instance, Goff et al (1990) found out that providing child-care place is not correlated to WFC. The empirical research by Liu Yongqiang and Zhao Shuming (2008), Chinese scholars, also showed that family care welfare is an ineffective formal enterprise system. However, if managers can support employees' work-family balance and avoid negative career consequence brought by enjoying family friendly programs welfare, WFC of employees will be greatly reduced.

Family friendly programs are not as effective as expected. The reasons come from many aspects. Perry-Smith et al (2000) held that family friendly programs are bundles. Single family friendly policy does not work. Only these bundles work together can play a certain role in balancing work and life. Furthermore, lacking of deep value of programs' implementation may be another reason. The above studies by Liu Yongqiang and Zhao Shuming indicated that "family friendly" has not become a common faith for Chinese governments, corporations and employees, and the family friendly system designing is still lack of social values foundation in China.

\subsection{Highly-committed work system}

According to HR management concept and the difference of its measurement, researchers classified HR management system into type of control and type of commitment (Batt, R. \& Valcour, P.M., 2003). The purpose of "type of control" system is to reduce labor cost and increase efficiency and with output for performance reward standard. "Type of commitment" is to develop and train highly-committing persons. And they believed that the employees can do well in their field. Based on this idea, the researchers launched some HR management measures associated with the training idea of "type of commitment", and called them "highly-committed work system". On the whole, highly-committed work system embodies three dimensions: HR stimulating scheme, work skill and work design.

Furthermore, researchers also study the relationship between highly-committed work system and WFC. Firstly, when an organization implements the stimulating scheme of highly-committed work system, the employees can get higher salary, work guarantee, and development opportunity. Stable income and guaranteed jobs can further satisfy the family' demands of the employees, so that WFC will be decreased (Raabe, P.H., 1990). On the contrary, unfair salary and staff cutting will cause unstable work and imbalance of work and family (Larson, J.H., et al, 1994). Secondly, the work skill training provided by organizations, such as the courses about self-control or 
career planning, can help staff improve the ability of confronting role conflict, and handle WFC at the same time. Moreover, work design contributes to promoting staff's ability of work control. So that when they are very busy or work overtime, they are very flexible to coordinate WFC. Meanwhile, work initiative also can help to reduce work stress (Galinsky, E. et al, 1996), so WFC will be relieved. As for the staff with children, the effect of work design is more significant. Team work is a common form of highly-committed work system. On the relationship between team work and WFC, the research results have not come into agreement. Some researchers think team work can promote staff's work flexibility. When some family need, staff can help each other even take over (Batt, R. \& Valcour, P.M., 2003). However, others think in an organization that emphasizes team work, because a plenty of things which need team discussion and communication, not only working hours will be prolonged, but also big pressure of team work will be produced, and consequently, WFC increased (Barker, J.R., 1993).

\section{The influence of variables of family}

Compared to influential factors of work, the research on the influence of family on WFC is much scarcer. The existing research on that mainly surrounds family demand \& stress, childcare responsibility, social support to family, connubial influence, and so on.

\subsection{Family demand and stress}

The research on family demand and stress can approximately be divided into two categories: one is from family structure or character to indirectly evaluate family demand or stress in order to forecast WFC; and the other is to investigate the subject integrated indicators of family demand or stress directly. Many researches about the forecasting effect of family character on FIW noticed that (Grzywacz, J. G., \& Marks, N. F., 2000) (Fox, M. L., \& Dwyer, D. J., 1999) the following people have higher FIW than others: family with children, with problems or puzzles of childcare, big-sized family, etc.

As an external object indicator, family character can influence WFC only through the family demand perceived by individuals subjectively. We shall firstly define and measure family demand if we want to study the relationship between family demand and WFC. Some definition is too narrow (Boyar, S.B. et al, 2003). For instance, they regard only the number of children as the standard of measuring family demand, or take Parents' role overload including number of children as an indicator. The disunion of operative definitions is the main reason that present researches can not come into agreement. When defining family demand, we should embody more complete factors and consider all the responsibilities of whole family members that individuals need to take on.

The reason why family demand influences WFC is variety of stresses produced as family demand is satisfied, such as role overload related to family role involvement, role conflict, and role vagueness. This stress from family level reduces the resources that can be used in work field. Individuals distribute the resource which should have been used in one role to another, which results in FIW and WIF. The individual, who spends a lot of time on family and takes on more exceptions as family role, will feel lack of working time and energy. High-level family demand may require individuals spend more time on family affair, which causes the related stress increases and spills over to work role, and thus increase FIW. Research showed overload of parents' role has significantly positive correlation with WIF and FIW (Frone, M. R. et al, 1997). High-FIW people have the following characteristics (Parasurman, S., \& Simmers, C. A., 2001): high involvement into family affair, much time demand from family, little support from family, disagreement with family or spouse, tensioned relationship, etc. Meta analysis on family variables shows family role conflict is significantly correlated with three types of FIW (time-based conflict, stress-based conflict and behavior-based conflict) while vagueness of family role has significant correlation with behavior-based FIW (Byron K., 2005).

\subsection{Childcare responsibility}

Having children is one of the basic functions and main responsibilities of a family. Therefore, as an important stress resource of family level, the study on childcare responsibility especially attracts attention. Although, theoretically speaking, childcare responsibility increases the possibility of FIW, real empirical tests are quite few. Childcare responsibility is usually measured by number of children in a family. Grandey et al (1999) achieved a research result indicated that the correlation of the number of children to FIW is high to 0.45. According to Theory of Resource Conservation, the more children a family has, the less time and energy will be involved into work. This phenomenon is particularly obvious in China (Luk, D. M., \& Shaffer, M. A., 2005).

Besides the number of children, age of children is another factor that needs to be focused on. The younger a child is, the more he or she is dependent on parents. Pre-school children need their parents to pay much more time and efforts. Infants and pre-school children have the highest requirements of time and energy of their parents 
(Bedeian, A.G. et al, 1988). Age of children has significant forecasting effect on WFC, moreover, and mother's WFC, but not on father's. Definitely speaking, a mother with 0-12-year-old children has highest WIF and FIW. While, when children grow up to 13-18 years old, the two types of WFC experienced by a mother both decrease obviously. However, in recent years, more and more studies demonstrate that WFC interfere not only females' but also males' (Eagle, B. W. et al, 1997).

\subsection{Social support to family}

What family demand variables emphasized are the possible factors producing WFC, and the opposite perspective is social support to family which might relieve the conflict. A study (Grzywacz, J. G., \& Marks, N. F., 2000) showed that family support (such as from spouse) has significantly negative correlation with FIW. Encourage, information and suggestion from family members all positively influence work role. Beatty also found out the main effect of spouse's support is obvious, and it can reduce WFC (Beatty, C. A., 1996). A study on Japanese professional females showed husbands' support can not play as a cushion between "demand as parents" and WFC (Matsui, T. et al, 1995). However, other study indicated spouse's support has a buffering role (Suchet, M., \& Barling, J., 1986)

An empirical research (Adams, G. A. et al, 1996) claimed that connubial support can be classified into emotional support and instrumental support. Emotional support mainly consists of empathy understanding and listening between husband and wife, sincere concern and recommendations, and so on. Instrumental support mainly refers to practical helps to housework and childcare. Instrumental support from spouse can relieve the burden of family demand and grant individual much more time on working. Emotional support from spouse can improve individual's efficacy in both family and work field. Several researches (Erdwins, C. J. et al, 2001) revealed that high-level connubial support and low-level WFC are significantly correlative. The female who obtains more emotional support from her husband has low level of conflict. Meanwhile, connubial support is especially influential to the reduction of FIW apparently (Adams, G. A. et al, 1996).

\subsection{Connubial influence}

Besides providing social support, husband and wife are also interactive in other aspects. If a female has different perception on work role salience from that of her husband, she will experience stronger WFC from heart. If her husband pays too much attention to work, her WFC will be much stronger (Beutell, N. J., \& Greenhaus, J. H., 1982). If husband is traditionally as gender role, family demand is much easier to arouse wife's WFC experience (Beutell, N. J., \& Greenhaus, J. H., 1983). Work role salience of husband and wife is significantly interactive to WFC. The interactive effect of job involvement of individual and his or her spouse can forecast male's time-based WFC together. In addition, career priority of husband and wife has significantly interactive and can forecast male's stress-based WFC together. When husband and wife both think his or her career priority is higher than the other, or lower than the other, male's stress-based WFC is higher, while female has no this efficacy(Greenhaus, J. H. et al, 1989).

In order to further research on how dual-earners confront WFC, Karambayya and Reilly (1992) applied qualitative and quantitative methods to investigate why and how people adjust their work so as to be more effectively confronted family's demand. They realized that work adjustment of couple is positively correlative even though wife may adjust more work than husband. Furthermore, the more they are involved into family, the more work adjustment they will make, for both males and females. There are various work adjustments, including adjusting working hours, working on weekend or at night, restrictions on business, care demand of both children and spouse. Meanwhile, those females with young children and high-income husband will adjust work more for family, but male has no this characteristic.

\section{Future prospects}

By reviewing the antecedents of work-family conflict, we conclude that through over two-decade accumulation, researchers have made a primary discovery on antecedent variables of work, family and individual, as the basic figure shows (see Figure 1). At the same time, we have to point out that present researches still have further spaces to fill out. We think the following problems should be paid much more special attention in the future.

\section{Insert figure 1 here}

\subsection{Strengthen theoretical construction and integrated research}

Through reviewing literature on WFC, we find that there are so few studies on raising or testing certain theory, and integrating researches on various variables. Most of researches are either based on present literature and propose some hypothesis, or raise own research structure based on a certain theory. But few scholars test one particular theory, or propose and test an integrated theoretical model, or elaborate the internal mechanism among 
variables deeply. Because of this, hypothesis testing research has enriched our knowledge on work-family relationship, but due to lack of theoretical core, these knowledge points are split and fragmented.

The weakness of WFC theory is owing to scarce discovery research at present. Discovery research is not to test some definite and particular hypothesis, but to achieve primary perception and understanding on some phenomenon. Therefore, it helps to identify and discover relevant variables and background to the phenomenon, so as to promote theoretical construction. Discovery research also contributes to emerging of some relation modes or repetitive questions, which is just another key factor of theoretical construction.

Theory should aims to answer "what", "how" and "why". We need to pay attention to deeply research on psychology and behavior in WFC field in order to promote theoretical construction. It is a pity that the large-scale review of Eby et al shows only a small percentage $(28 \%)$ of forecasting research involves mediators (Eby,L. T. et al, 2005). Therefore, we should not only strengthen exploratory research but also integrate research on various mediators and crossing individual, family and organization (work) to drive theoretical construction.

\subsection{Research on influential factors remains to be refined}

WFC is a rich, multi-dimensional and multi-level concept. Firstly, the antecedent variables of time-based, stress-based and behavior-based conflict are different. Scholars have imbalance on attention to these three types of conflict. Time-based conflict and stress-based one comparatively attract more attention. But behavior-based conflict is very lack of studies (Dierdorff, E. C., \& Ellington, J. K., 2008). Some Meta analysis also demonstrated the statement (Ford, M. T. et al, 2007). So we have to enhance the research on behavior-based WFC.

Additionally, the influential factors on WIF and FIW are different. The two types of conflict have interactive effects on each other (Anderson, S. E. et al, 2002). Work and family are two-way interactive, which is perceived comparatively late in the field. So it indicates the complexity of the concept of WFC. However, most of the existing researches on work-family still apply nondirectional and integrated WFC measurement indicators. These nondirectional scales mix WIF and FIW, so it is very difficult to distinguish them. Happily, some scholars, in their new-launched WFC scales, not only involve WIF and FIW from effect direction perspective, but also embody time-based, stress-based and behavior-based conflict from conflict source perspective (Carlson,D.S.,\& Kacmar, K. M., 2000). So along with the increasing enrichment and continuous development of concept level of WFC, we have to make more elaborate research on its antecedent variables based on sub-dimensions, otherwise, the internal and external efficacies of research are going to decrease.

\subsection{Research on effect of subject perception of roles remains to be strengthened}

A variety of forecasting sources involved in present research are mostly objective variables, such as work character and family friendly programs in work field, and number of children, marital status and spouse's work status in family field. However, the objective characters of individual role, such as manager position, being parents, can hardly grasp and entirely reflect the complexity of work-family role. We take "having children or not" as an example. This indicator is usually used to infer what family responsibility an individual needs to take on. However, what do "children" bring to parents? They might be responsibility and stressor, or emotional support. So only regarding "having children or not" as a rough indicator of family role can not reflect what family role requires individuals and brings to them. In addition, even if it is discovered that "number of children" (an objective indicator of family character) is significantly correlative with WFC, we still don't know how, why and under what condition children influence WFC. Therefore, future research should focus more on individual subjective perception on roles, such as importance and value perception of roles.

\subsection{Research with "couples" as a unit should be taken into account}

There is no doubt that "couples" are the most important bases of a family. Couples are interactive to each other and influence respective work-family experience together. The relationship between work and family is obviously not individual problem, but couples' corporate problem. There is a very early research on the influence of couple's interactive mode on work-family relationship (Handy, C., 1978). Afterward, Hammer et al (1997) also noticed the important transfer effect of couples on WFC. They claimed to develop similar research with "couples" as a unit. Couples can adjust or enhance their feelings on work-family and their relations through understanding each other, communication on knowledge and idea, emotional dependence, profound feelings, and so on. However, for present research, only a few researchers look upon "couples", but not individual, as research unit. Therefore, we should emphasize on the research with "couples" as unit so as to improve scientificity and ecological validity of the research. 


\subsection{Strengthen the research based on Chinese culture and social background}

Hofstede defines culture as "mutual spirit program of a group of people". Human's thought, emotion and behavior are all in accordance with "program" to reflect particular mode of one society (Hofstede, G.). Why do people work? What does family mean to people? The answers to these important questions about life must be painted with strong cultural colors. The work value, family value and individual time value in Western individualistic society and Eastern collectivistic society are all different. As for work value, Chinese believe that the purpose of work is to obtain self-satisfaction, economic independence and needs of raising family. So income is what Chinese most emphasize on work value. While, American focus most on vocational interest, secondly, achievement, development, individual growth and respect (Holt, J. \& Keats, D. M., 1992). As far as family value concerned, Chinese have the cultural tradition of "big family", like "four generations in a family" and "family happiness". The activity of "five-good family" also reflects the continuity of family values of filial piety, respect to the old, cooperation and harmony in Confucian culture. The researches on American family value have conflict. Although the majority of researches show that American think family is the most important part in one's life, many researchers state that most American will place work and personal freedom beyond family responsibility (Dora, L.M., 2001). Furthermore, "single child" and the education idea of high expectation on one's child are the particular family culture phenomenon of Chinese. In addition, compared to Western countries, China has low labor cost, which enable house service plays an important role in family. According to the above stated, the work value, family value and social background in the West and East might be different, which influence the work-family relationship.

However, present researches on work-family problems are mainly based on Western culture and value, so there must be big limitations. We should develop the research from different cultural perspectives in order to scientifically reveal the system and the whole phenomenon of WFC in deed.

\subsection{Weak research on the influence of variables in field of individual and family}

As far as antecedent variables are concerned, the researches on influential factors of work are far more than that of family and individuals. Actually, variables of family and individuals have too much to pay attention to. For example, among variables of family, husband-wife relationship, parents-children relationship, education mode and children's behavior all may influence work-family relationship, which is worth to being studied in the future. As for individual differences, there are abundant scientific topics to be concerned. Parker and Hall appealed very clearly that the research on work-family problems should focus on "self" (Parker, V. A., \& Hall, D. T., 1992). Psychology of industry and organization has the tradition of emphasizing individual difference, while the researches on work-family problems do not pay enough attention to individual personality, value and motivation. Individual growing experience, parent's education experience, career experience, friendship, and gender relations all might influence WFC by influencing "self", which are worth to be well discussed in the future.

\section{References}

Adams, G. A., King, L. A., \& King, D. W. (1996). Relationships of job and family involvement, family social support, and work-family conflict with job and life satisfaction. Journal of Applied Psychology. 81(4): 411-420.

Adams, G.A., \& Jex, S.M. (1999). Relationships between time management, control, work-to-family conflict and strain. Journal of Occupational Health Psychology. 4 (1): 72-79.

Anderson, S. E., Coffey, B. S., \& Byerly, R. T. (2002). Formal organizational initiatives and informal workplace practices: Links to work-family conflict and job-related outcomes. Journal of Management. 28. 787-810.

Andreassi, J.K. (2006). The role of personality and coping in work-family conflict: new directions, Unpublished Doctoral Dissertation, The City University of New York. 99.

Aryee, S., Fields, D., \& Luk, V. (1999). A cross-cultural test of a model of the work-family interface. Journal of Management. 25: 491-511.

Aryee, S., Luk, V., Leung, A., \& Lo, S. (1999). Role stressors, interrole conflict, and well-being: The moderating influence of spousal support and coping behaviors among employed parents in Hong Kong. Journal of Vocational Behavior, 54: 259-278.

Bandura, A. (1977). Self-efficacy: Toward a unifying theory of behavioral change. Psychological Review, 84: 191-215.

Barker, J.R. (1993). Tightening the iron cage: concertive control in self-managing teams. Administrative Science Quarterly, 38(3): 408-437.

Batt, R., \& Valcour, P.M. (2003). Human resource practices as predictors of work-family outcomes and 
employee turnover. Industrial relations, 42(2): 189-220.

Beatty, C. A. (1996). The stress of managerial and professional female: Is the price too high? Journal of Organizational Behavior, 17: 233-251.

Bedeian, A.G., Burke, B.G., \& Moffett, R.G. (1988). Outcomes of work-family conflict among married male and female professional. Academy of Management Journal, 14: 476-491.

Behson, S. J. (2002). Coping with family-to-work conflict: The role of informal work accommodations to family. Journal of Occupational Health Psychology, 7: 324-341.

Bernas, K. H., \& Major, A. D. (2000). Contributors to stress resistance: Testing a model of female's work-family conflict. Psychology of Female Quarterly, 24: 170-178.

Beutell, N. J., \& Greenhaus, J. H. (1982). Interrole conflict among married female: The influence of husband and wife characteristics on conflict and coping behavior. Journal of Vocational Behavior, 21: 99-110.

Beutell, N. J., \& Greenhaus, J. H. (1983). Integration of home and non-home roles: Female's conflict and coping behavior. Journal of Applied Psychology, 68: 43-48.

Beutell, N., \& Wittig-Berman, U. (1999). Predictors of work-family conflict and satisfaction with family, job, career, and life. Psychological Reports, 85: 893-903.

Boyar, S.B., Maertz, C.P. Pearson, A.W., \& Keough, S. (2003). Work-family conflict: A model of linkages between work and family domain variables and turnover intentions. 15(2): 175-191.

Bruck, C.S., \& Allen, T.D. (2003). The relationship between big five personality traits, negative affectivity, type A behavior, and work-family conflict. Journal of Vocational Behavior, 63: 457-472

Burke, R.J. (1999). Workaholism and extra-work satisfactions. International Journal of Organizational Analysis, 7(4): 352-365.

Byron, K. (2005). A meta-analytic review of work-family conflict and its antecedents. Journal of Vocational Behavior, 67: 169-198.

Caplan, R. D., Cobb, S., French, J., Harrison, R., \& Pinneau, R. (1975). Job demands and worker health. Washington, DC: U.S. Government Printing Office. DHEW Publication, 75-160.

Carlson, D.S., \& Kacmar, K. M. (2000). Work-family conflict in the organization: Do life role values make a difference? Journal of Management, 26(5): 1031-1054.

Carnicer, M.P.D., Sanchez, L.A. M., \& Perez, M. P. (2004). Work-family conflict in a southern European country: The influence of job-related and non-related factors. Journal of Managerial Psychology, 19(5): 466-490.

Chen Hua, Tan Kaiyi and Liang Yanjun. (2007). On work-family conflict and self-efficacy. Guizhou Normal University, 05

Chen, Weizheng, Li Guiqing \& Wu Jihong. (2007). On effect of work share on promoting balance of work and life. China Industrial Economy, 6: 5-12.

Cinamon, G.R. (2006). Anticipated work-family conflict: Effects of gender, self-efficacy, and family background. The Career Development Quarterly, 54: 202-215.

Cinamon, G.R., Weisel, A., \& Tzuk, K. (2007). Work Family Conflict Within the Family: Crossover Effects, Perceived Parent Child Interaction Quality, Parental Self-Efficacy, and Life Role Attributions. Journal of Career Development, September: 79-100

Clark, S. C. (2002). Employees-sense of community, sense of control, and work/family conflict in Native American organizations. Journal of Vocational Behavior, 61: 92-108.

Dierdorff, E. C., \& Ellington, J. K. (2008). It's the Nature of the Work: Examining Behavior-Based Sources of Work-Family Conflict across Occupations. Journal of Applied Psychology, 93(4): 883-892.

Dora, L.M. (2001). An investigation of work-family conflict: A Cross-Cultural Comparison. Unpublished Doctoral Dissertation, Department of Management, the Hong Kong Polytechnic University. 3-25.

Duxbury, L. E., \& Higgins, C. A. (1991). Gender differences in work-family conflict. Journal of Applied Psychology, 76: 60-73.

Eagle, B. W., Miles, E. W., \& Icenogle, M. L. (1997). Inter-role conflicts and the permeability of work and family domains: Are there gender differences? Journal of Vocational Behavior, 50: 168-184. 
Eby, L. T., Casper, W. J., Lockwood, A., Bordeaux, C., \& Brinley, A. (2005). Work and family research in IO/OB: Content analysis and review of the literature (1980-2002). Journal of Vocational Behavior, 66: 124-197.

Erdwins, C. J., Buffardi, L. C., \& Casper, W. J. (2001). The relationship of female's role strain to social support, role satisfaction, and self-efficacy. Family Relations, 50: 230-238.

Erdwins, C.J., Buffardi, L.C., Casper, W.J., \& O’Brien, A.S. (2001). The relationship of female's role strain to social support, role satisfaction, and self-efficacy. Family Relations, 50 (3): 230-239

Ford, M. T., Heinen, B. A., \& Langkamer, K. L. (2007). Work and family satisfaction and conflict: A meta-analysis of cross-domain relations. Journal of Applied Psychology, 92: 57-80.

Fox, M. L., \& Dwyer, D. J. (1999). An investigation of the effects of time and involvement in the relationship between stressors and work-family conflict. Journal of Occupational Health Psychology, 4: 164-174.

Frone, M. R., Russell, M., \& Cooper, M. L. (1997). Relation of work-family conflict to health outcomes: A four-year longitudinal study of employed parents. Journal of Occupational and Organizational Psychology, 70: 325-335.

Frone, M.R. (2000). Work-family conflict and employee psychiatric disorders: The national comorbidity survey. Journal of Applied Psychology, 85(6): 888-895.

Frone, M.R., Yardley,J.K., \&Markel, K.S. (1997). Developing and testing an integrative model of work-family interface. Journal of Vocational Behavior, 50: 146-167.

Fu, C.K., \& Shaffer, M.A. (2001). The tug of work and family: direct and indirect domain specific determinants of work-family conflict. Personnel Review, 30(5): 502-522.

Gajendran, R.S., \& Harrison, D.A. (2007). The Good, the Bad, and the Unknown About Telecommuting: Meta-Analysis of Psychological Mediators and Individual Consequences. Journal of Applied Psychology, 92(6): 1524-1541.

Galinsky, E., Bond, J.T., \& Friedman, D.E. (1996). The role of employers in addressing the needs of employed parents. Journal of Social Issue, 52(3): 111-136.

Goff, S. J., Mount, M. K., \& Jamison, R. L. (1990). Employer supported child care, work/family conflict, and absenteeism: A field study. Personnel Psychology, 43. 793-809.

Grandey, A. A., \& Cropanzano, R. (1999). The conservation of resources model applied to work-family conflict and strain. Journal of Vocational Behavior, 54: 350-370.

Greenhaus, J. H., \& Beutell, N.J. (1985). Sources of Conflict between Work and Family Roles. Academy of Management Review, 10(1): 76-88.

Greenhaus, J. H., Bedeian, A.G., \& Mossholder, K.W. (1987). Work experiences, job performance, and feelings of personal and family well-being. Journal of Vocational Behavior, 31: 200-215.

Greenhaus, J. H., Parasuraman, S., Granrose, C. S., Rabinowitz, S., \& Beutell, N. J. (1989). Sources of work-family conflict among two-career couples. Journal of Vocational Behavior, 34: 133-153.

Grzywacz, J. G., \& Marks, N. F. (2000). Reconceptualizing the work-family interface: An ecological perspective on the correlates of positive and negative spillover between work and family. Journal of Occupational Health Psychology, 5: 111-126.

Gutek, B. A., Searle, S., \& Klepa, L. (1991). Rational Versus Gender Role Explanations for Work family Conflict. Journal of Applied Psychology, 76: 560-568.

Hall, D. T., \& Richter, J. (1988). Balancing life and home life: What can organizations do to help? Academy of Management Executive, 11: 213-223.

Hammer, L.B., Allen, E., \& Grigsby, T.D. (1997). Work-family conflict in dual-earner couples: Within individual and crossover effects of work and family. Journal of Vocational Behavior, 50: 185-203.

Handy, C. (1978). The Family: Help or Hindrance? In Cooper, C.L. \& Payne, R. (1978). Stress at work. John Wiley \& Sons, Ltd. 107 - 123.

Hennessy, K. D. (2007). Work-family balance: an exploration of conflict and enrichment for female on a traditional occupation. Unpublished Doctoral Dissertation, College Park, University of Maryland. 44-50.

Higgins, C., Duxbury, L., \& Lee, C. (1994). Impact of life-cycle stage and gender on the ability to balance work and family responsibility. Family Relations, 43(2): 144-150. 
Hobfoll, S.E. (1989). Conservation of resources: A new attempt at conceptualizing stress. American Psychologist, 44(3): 513-524.

Hofstede, G. (1984). Culture's consequences: International differences in work-related values. Beverly Hills, CA: Sage.

Holt, J. \& Keats, D. M. (1992). Work cognition in multicultural interaction. Journal of Cross-Cultural Psychology, 23(4): 421-443.

Karambayya, R., \& Reilly, A. H. (1992). Dual earner couples: Attitudes and actions in restructuring work for family. Journal of Organizational Behavior, 13: 585-601.

Kirchmeyer, C. (1998). Determinants of managerial career success: Evidence and explanation of male/female differences. Journal of Management, 24: 673-692.

Larson, J.H., Wilson, S.M., \& Beley, R. (1994). The impact of job insecurity on marital and family relationships. Family Relations, 43: 138-143.

Liu, Yongqiang, Zhao, Shuming \& Wang, Yonggui. (2008). Arrangement of enterprise system based on work-family balance. China Industrial Economy, 2: 85-94.

Luk, D. M., \& Shaffer, M. (2005). A. Work and family domain stressors and support: Within- and cross-domain influences on work-family conflict. Journal of Occupational and Organizational Psychology, Dec 78: 489-499.

Lundberg, U., \& Frankenhaeuser, M. (1999). Stress and workload of male and female in high-ranking positions. Journal of Occupational Health Psychology, 4: 142-151.

Luo, Yaoping, Fan, Huiyong and Zhang, Jinfu. (2007). Antecedents, consequences and intervention strategies on work - family conflict. Psychological Science, 15 (6): 930-937

Matsui, T., Ohsawa, T., \& Onglatco, M. L. (1995). Work-family conflict and the stress-buffering effects of husband support and coping behavior among Japanese married working female. Journal of Vocational Behavior, 47: 178-192.

Matsui, T., Tsuzuki, Y., \& Onglatco, M. L. (1999). Some motivational bases for work and home orientation among Japanese college female: A rewards/costs analysis. Journal of Vocational Behavior, 54: 114-126.

McMillan, L.H.W., Brady, E.C., O’Driscoll, M.P., \& Marsh, N.V. (2002). A multifaceted validation study of Spence and Robbins' (1992) Workaholism battery. Journal of Occupational and Organizational Psychology, 75(3): 357-368.

Milkie, M. A., \& Peltola P. (1999). Playing All the Roles: Gender and the Work-Family Balancing Act. Journal of Marriage and the Family, 61(2): 476-490.

Netemeyer, R.G., Boles, J.S., \& McMurrian, R. (1996). Development and Validation of Work-family conflict scales. Journal of Applied Psychology, 81(4): 400-410.

Nielson, T. R., Carlson, D. S., \& Lankau, M. J. (2001). The supportive method as a means of reducing work-family conflict. Journal of Vocational Behavior, 59: 364-381.

Northcraft, G. B., Huber, V., \& Neale, M. A. (1988). Sex effects in performance-related judgements. Human Performance, 1: 161-175.

Olson-Buchanan, J., \& Boswell, W. (2006). Blurring boundaries: Correlates of integration and segmentation between work and non-work. Journal of Vocational Behavior, 68: 432-445.

Parasurman, S., \& Simmers, C. A. (2001). Type of employment, work-family conflict and well-being: A comparative study. Journal of Organizational Behavior, 22: 551-568.

Parker, V. A., \& Hall, D. T. (1992). Conclusion: Expanding the domain of family and work issues. In S.Zedeck (Ed.), Work, families and organizations. San Francisco, CA: Jossey Bass. 1992.

Perkins, H. W., \&DeMeis, D. K. (1996). Gender and Family Effects on the" Second Shift" Domestic Activity of College-Educated Young Adults. Gender and Society, 10(1): 78-93.

Perry-Smith, J., \& Blum, T. (2000). Work-Family Human Resource Bundles and Perceived Organizational Performance. Academy of Management Journal, 43(6): 1107-1117.

Raabe, P.H. (1990). The organizational effects of workplace family police. Journal of Family Issues, 11(4): 477-491.

Russo, J.A., \& Waters, L.E. (2006). Workaholic worker type differences in work-family conflict: the moderating 
role of supervisor support and flexible work scheduling. Career Development International. 11(5): 418-439.

Sanik, M. (1993). The effects of time allocation on parental stress. Social Indicators Research, 30: 175-84.

Shafiro, M. (2004). The effect of allocentrism, idiocentrism, social support, and big five personality dimensions on work-family conflict. Unpublished Doctoral Dissertation, Portland State University. 131-132.

Simon, R. W. (1995). Gender, multiple roles, role meaning, and mental health. Journal of Health and Social Behavior. 36: 182-194.

Spence, T.J., \& Robbins, A.S. (1992). Workaholism, measurement and preliminary results. Journal of Personality Assessment. 58(1): 160-178.

Stoner, C.R., Hartman, R.L., \& Arora, R. (1991). Work/family conflict: A study of female in management. The Journal of Applied Business Research, 7(1): 67-74.

Suchet, M., \& Barling, J. (1986). Employed mothers: Interrole conflict, spouse support, and marital functioning. Journal of Occupational Behavior, 7:167-178.

Tenbrunsel, A. E., Brett, J. M., Maoz, E., \& Stroh, L. K. (1995). Dynamic and static work-family relationships. Organizational Behavior and Human Decision Processes, 63: 233-246.

Thomas, L.T., and Ganster, D.C. (1995). Impact of family-supportive work variables on work-to-family conflict and strain: a control perspective. Journal of Applied Psychology, 80 (1): 6-15.

Thompson, C.A., Beauvais, L. L., \& Lyness, K. S. (1999). When work-family benefits are not enough: The influence of work-family culture on benefit utilization, organizational attachment, and work-family conflict. Journal of Vocational Behavior, 54: 392-415.

Voydanoff, P., \& Kelly, R.F. (1984). Determinants of work-related family problems among employed parents. Journal of Marriage and the Family, 46: 881-892.

Wallace, J. E. (1999). Work-to-nonwork conflict among married male and female lawyers. Journal of Organizational Behavior, 20, 797-816.

Wayne, J. H., Musisca, N., \& Fleeson, W. (2004). Considering the role of personality in the work-family experience: Relationships of the big five to work-family conflict and facilitation. Journal of Vocational Behavior, 64: 108-130.

Werbel, J. (1998). Intent and choice regarding maternal employment following childbirth. Journal of Vocational Behavior, 53: 372-385.

Wood, R., \& Bandura, A. (1989). Impact of Conceptions of Ability on Self-Regulatory Mechanisms and Complex Decision Making. Journal of Personality and Social Psychology, 56(3) 407-415.

Yang, N., Chen, C. C., Choi, J., \& Zou, Y. (2000). Sources of work-family conflict: A Sino-U.S. comparison of the effects of work and family demands. Academy of Management Journal, 43: 113-123.

Yu, Shuguang. (2008). On the relationship of WFC to work/family satisfaction and happiness: the effect of self-efficacy. A master's degree thesis. University of International Business and Economics. 36-44. 


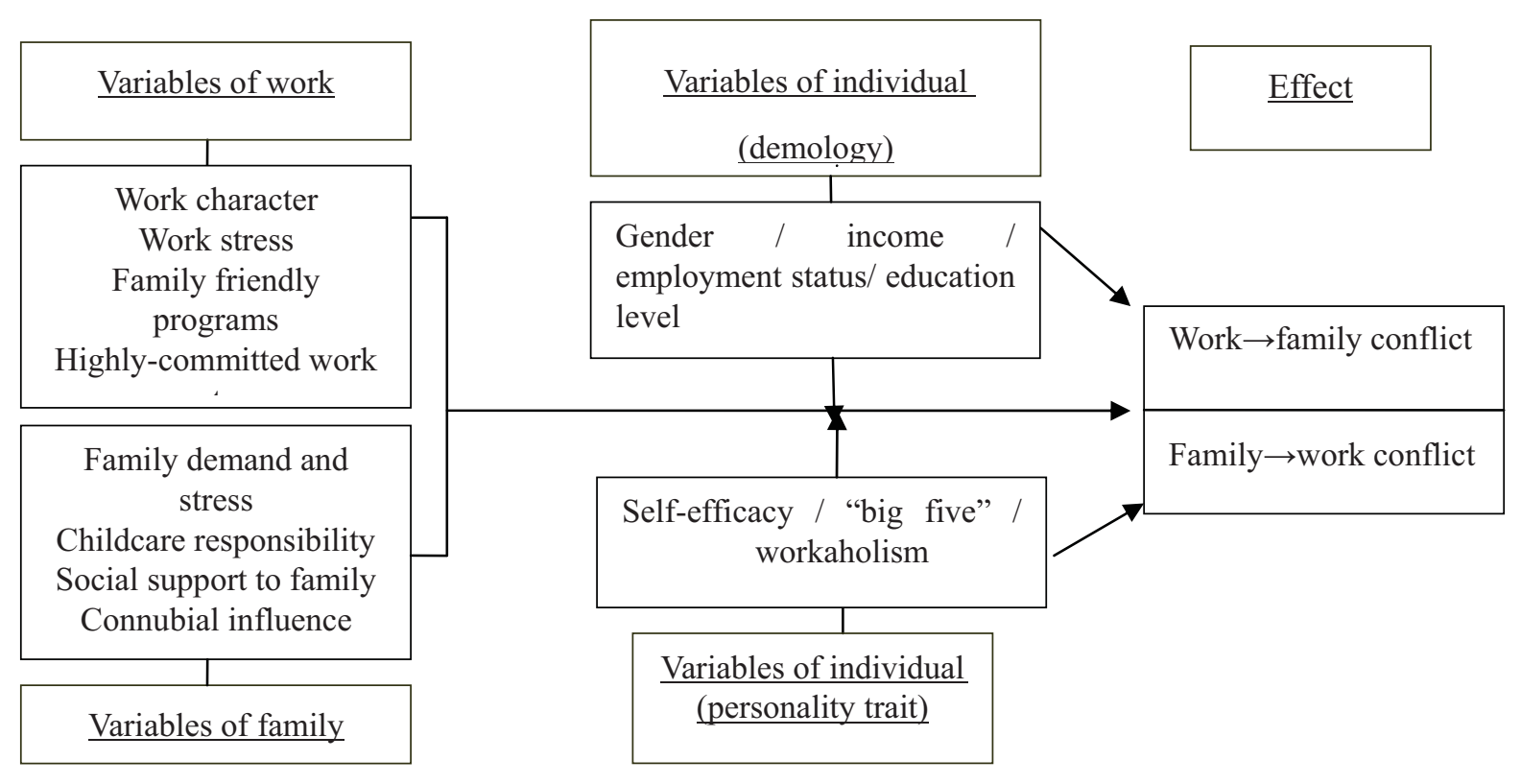

Figure 1. Theoretical model on influential factors to WFC

Data source: summary by the author 